\title{
Quantification and purification of lutein and zeaxanthin recovered from distillers dried grains with solubles (DDGS)
}

\author{
Jinsha Li ${ }^{1}$ and Abigail S. Engelberth ${ }^{1,2^{*}}$ (1)
}

\begin{abstract}
Marigold petals, the current commercial source for lutein and zeaxanthin are harvested through a labor-intensive operation with downstream purification requiring multiple processing steps involving various harsh solvents. Lutein and zeaxanthin are in-demand carotenoids due to their significant role in human eye health. A possible alternative source for lutein and zeaxanthin, distillers dried grain with solubles (DDGS), shows promise and contains a yet-to-be quantified amount of the desired carotenoids. The US corn industry produces an abundant, and in some cases excess, annual supply of DDGS. The large volume of DDGS produced could serve as a significant source for lutein and zeaxanthin recovery and provides an additional market stream for the growing carotenoid industry. This paper demonstrates one of the first quantitative reports regarding the concentration of lutein and zeaxanthin in DDGS. Using Soxhlet extraction, followed by purification with centrifugal partition chromatography, it was determined that $36.09 \pm 16.87 \mu \mathrm{g}$ lutein and $15.48 \pm 6.13 \mu \mathrm{g}$ zeaxanthin could be purified from all extractives retained in the oleoresin per gram of DDGS. As compared to lutein and zeaxanthin present in corn, this is a three to fivefold increase indicating that these compounds become concentrated during the dry grind process. Recovery of lutein and zeaxanthin from DDGS, a low-value stream by-product of corn ethanol industry, results in a new revenue stream and would add value to a common US commodity.
\end{abstract}

Keywords: Carotenoids, Value added, Extraction, CPC purification

\section{Background}

Lutein and zeaxanthin are xanthophyll plant carotenoids that have a demonstrated positive role in human eye health. Primates are unable to synthesize lutein and zeaxanthin, and therefore must rely on dietary sources for absorption (Malinow et al. 1980; Johnson et al. 2005). Lutein and zeaxanthin are present throughout body tissue and are the only carotenoids found in macular region of retina (John et al. 2002). Along with astaxanthin and beta-carotene, lutein and zeaxanthin have demonstrated a beneficial role in eye health (Fullmer and Shao 2001; Koushan et al. 2013). There is increasing evidence to

\footnotetext{
*Correspondence: aengelbe@purdue.edu

${ }^{1}$ Laboratory of Renewable Resources Engineering, Department

of Agricultural and Biological Engineering, Purdue University, Potter Engineering Building, Room 216, 500 Central Drive, West Lafayette, IN 47907, USA

Full list of author information is available at the end of the article
}

support the important role lutein and zeaxanthin play in preventing and/or ameliorating chronic disease, including certain cancers, age-related degenerative disease, and some cardiovascular disease (Bone et al. 1985).

The U.S. market for lutein is on the rise. Lutein, sold as a feed additive in the form of a food colorant, is a nearly $\$ 150$ million/year (Delgado-Vargas and Paredes-López 2002) industry. The global market for lutein was estimated to be worth $\$ 233$ million in 2010 and is expected to grow by $3.6 \%$ annually (BCC Research 2011). Currently, commercially available lutein products are extracted from the petals of the marigold flower, Tagetes erecta (Delgado-Vargas and Paredes-López 1996). When extracted from $T$. erecta, lutein and zeaxanthin are both in a diester form, but can be saponified and then concentrated and recrystallized into an onerous crystalline form (Khachik 2001; Fernández-Sevilla et al. 2010). In addition, recovery of lutein and zeaxanthin from marigold is labor 
intensive since the petals must be separated from the flower and the content within the petals is variable and can be as low as $0.17 \mathrm{mg} / \mathrm{g}$ (Piccaglia et al. 1998; Fernández-Sevilla et al. 2010). The additional processing steps required for lutein and zeaxanthin extracted from marigold to be viable in a dietary supplement raises questions regarding using marigold as the sole lutein source. Thus, there is a pressing need to identify a new, stable, and consequential supply for lutein and zeaxanthin, along with a more proficient extraction method.

Lutein is found in a variety of food sources, generally those that are yellow or orange in nature, but exist in the highest abundance in dark green leafy vegetables such spinach or kale (Sommerburg et al. 1998). Zeaxanthin is present in limited dietary sources, including corn, papaya, orange, nectarine, and other yellow-orange fruits (Mozaffarieh et al. 2003). When looking specifically at corn as a source for lutein and zeaxanthin, it has been reported that maize contains an average of $5.95 \mu \mathrm{g}$ lutein and $2.16 \mu \mathrm{g}$ zeaxanthin per g dry weight (Kurilich and Juvik 1999). Additional reports determined that together, lutein and zeaxanthin account for $70 \%$ of the total carotenoids found in corn milled fractions (Kean et al. 2011). Studies have also quantified the total carotenoid content in corn ( $\mathrm{Li}$ et al. 2007; Chauveau-Duriot et al. 2010) to be as high as $30 \mathrm{mg} / \mathrm{kg}$, of which lutein and zeaxanthin dominate. Distillers dried grains with solubles (DDGS), the solids fraction remaining after the dry-grind process during corn ethanol production, has been reported to contain a threefold increase of xanthophylls compared to corn entering the process (Bregendahl 2008). Evidence demonstrates that since corn contains a noticeable quantity of lutein and zeaxanthin, then DDGS and its corresponding oleoresin $-\mathrm{a}$ condensed extract containing ethanol soluble compounds-must also contain a noticeable quantity of lutein and zeaxanthin. While the existence of an extractable amount of lutein and zeaxanthin in DDGS is promising, information on direct quantification of these two compounds is limited. Evidence from an animal feed study-when DDGS was increased from 0 to $50 \%$ blending ratio in feed, the average lutein concentration measured in the egg yolk increased from 6 to $17 \mathrm{mg} / \mathrm{g}$ (Sun et al. 2013)-indicates that the quantity of lutein and zeaxanthin in DDGS is notable.

The utility of DDGS as a source of extractable lutein and zeaxanthin was studied. The goal was to determine if DDGS is a viable option to meet the need of a growing global carotenoid market while adding a revenue stream to corn ethanol industry. Any additional technology to recover lutein and zeaxanthin from DDGS must preserve and augment the current animal feed market stream to be successfully implemented. The specific objectives to meet this goal were: (1) to determine the mass of concentrated lutein and zeaxanthin remaining in the oleoresin after Soxhlet extraction of DDGS and (2) to purify lutein and zeaxanthin from extractives using centrifugal partition chromatography (CPC). This study confirms the quantity of lutein and zeaxanthin remaining the DDGS and demonstrates a method to quickly produce a pure fraction of lutein and zeaxanthin from crude extract.

\section{Methods \\ Materials}

DDGS sample $-\sim 10 \%$ moisture content-was obtained from Anderson Clymers Ethanol Plant, Logansport, IN and refrigerated at $5{ }^{\circ} \mathrm{C}$. High-performance liquid chromatography (HPLC) grade solvents, ethyl alcohol (190 proof, KOPTEC), ethyl acetate (J. T. Baker), methyl alcohol (Macron), heptane (Sigma-Aldrich), and acetonitrile (Sigma-Aldrich) were used for analysis. For HPLC mobile phase preparation, ammonium acetate (Sigma-Aldrich) with $>98 \%$ purity and was stored in $2-8{ }^{\circ} \mathrm{C}$. Lutein and zeaxanthin standards were purchased from INDOFINE Chemical Company Inc., Hillsborough, NJ. Kemin Industries (Des Moines, IA) donated a sample carotenoid, containing an undisclosed concentration of lutein and zeaxanthin, to use for methods testing.

\section{Compound solubility tests}

It was necessary to determine solvents in which lutein and zeaxanthin were highly soluble for both Soxhlet extraction and CPC purification. Five solvents (methanol, ethyl acetate, ethanol, acetonitrile, and water), commonly used within solvent systems aimed to purify polar compounds, were tested. To determine solubility of lutein and zeaxanthin within each solvent, $10 \mathrm{mg}$ of Kemin sample was added to $20 \mathrm{~mL}$ of solvent and was vigorously mixed. The solution was then allowed to settle and equilibrate $1 \mathrm{~h}$. A $1 \mathrm{~mL}$ aliquot of each solution was extracted and the solvent was allowed to evaporate fully under nitrogen. Lutein and zeaxanthin, and other components in the sample, were not volatile and remained in the test tube after evaporation. HPLC mobile phase $(1 \mathrm{~mL})$ was then added to the evaporated sample and analyzed via HPLC. The sample was not directly injected onto the HPLC column in the extraction solvent because the extraction solvent would have interfered with the HPLC analysis. Solubility was performed in this way due to the relative complexity of the sample. The sample provided by Kemin contained compounds beyond lutein and zeaxanthin including visible particles that were insoluble in the extraction solution. In addition, the sample was not filtered during the solubility test to ensure that all possible lutein and zeaxanthin was available for testing and not lost to a membrane. Samples were filtered with a $0.45 \mu \mathrm{m}$ syringe filter (CR25 mm PTFE membrane filter, 
PALL) prior to injection to the HPLC column. The concentration of lutein and zeaxanthin was calculated and it was determined that ethyl acetate and ethanol were the solvents in which the compounds were most soluble (Table 1). This is not a report of absolute solubility, but rather relative solubility for the sake of comparison and extraction solvent choice. The yield is included in Table 1 to demonstrate both that lutein and zeaxanthin content in the Kemin sample was relatively low and to be able to compare solubility. Due to the favorable solubility of both lutein and zeaxanthin, ethanol was the chosen solvent for Soxhlet extraction.

\section{Extraction and sample preparation}

DDGS, supplied by The Andersons (Clymers Plant, Logansville, IN), was reduced using coffee grinder and sieved manually to 20,40 , or 60 mesh. A single thickness cellulose thimble (GE Whatman, $25 \times 90 \mathrm{~mm}$ ) held the DDGS sample during Soxhlet extraction. The experimental conditions for Soxhlet extraction were modified from the NREL Laboratory Analytical Procedure (LAP) for determination of Extractives in Biomass (NREL/ TP-510-42619) (Sluiter et al. 2008), in which chlorophyll, waxes, or other minor components dissolved in organic solvent through ethanol extraction could be analyzed. The extraction was adjusted to attain 6-10 siphon cycles per hour throughout the process to allow for sufficient sample and solvent interaction. Raw DDGS samples, $9 \pm 0.5 \mathrm{~g}$, were size-reduced to 20,40 , and 60 mesh to meet the minimum size requirement suggested by the NREL protocol (Sluiter et al. 2008). Ethanol was refluxed through the Soxhlet with $8 \pm 1$ reflux cycles per hour for $4 \mathrm{~h}$ to solubilize the lutein and zeaxanthin from the DDGS. The oleoresin and ethanol were recovered in a round-bottom flask. The ethanol was then evaporated from the oleoresin using a rotary evaporator (Glas-Col 009A EV2012S, Vol: 120 vac, $60 \mathrm{~Hz}$, Amps 2). Oleoresin was further analyzed by HPLC and CPC. The oleoresin adhered flask wall during evaporation and required an additional $10 \mathrm{~mL}$ of solvent-either HPLC or CPC mobile phase-plus $5 \mathrm{~min}$ in an ultrasonic bath to release into the solution. The mixture of oleoresin and CPC solvent was filtered using a $0.45 \mu \mathrm{m}$ syringe filter (CR25 mm PTFE membrane filter, PALL) before further analysis by either HPLC or purification via CPC.

\section{DDGS characterization}

A compositional analysis was performed on raw DDGS and post-extraction samples to examine how the extraction process alters the sample. The wet cake post-extraction was dried in a $45{ }^{\circ} \mathrm{C}$ oven overnight. Compositional analysis was performed by A\&L Greatlakes Laboratories (Ft. Wayne, IN). Analysis for each sample included: dry matter (AOAC 967.03), acid detergent fiber (ADF) (AOAC 973.18), neutral detergent fiber (NDF) (NFTA method 5.1), crude fiber (AACC 30-20), hemicellulose (AOAC 973.18), lignin (AOAC 973.18), cellulose (AOAC 973.18), crude fat (AACC 32-10), ash (AOAC 942.05), and total starch (Belyea et al. 2004).

\section{Analytical methods \\ HPLC analysis}

A C30150 $\times 2.0 \mathrm{~mm}$ I.D. $\mathrm{s}-3 \mu \mathrm{m}$ polymeric column (YMC Co. LTD), with a guard column containing the same stationary phase, was used for HPLC (Waters 1525 Binary HPLC pump, waters 717 Plus Autosampler, Waters 2498 UV/Visible Light detector) analysis. The mobile phase consisted of solvent $\mathrm{A}$ at methanol/ammonium acetate $(98: 2, v / v)$ and solvent B at $100 \%$ ethyl acetate. The flow rate of mobile phase was $0.37 \mathrm{~mL} / \mathrm{min}$ set at the following linear gradient: \%B: $0-80 \%(0-10 \mathrm{~min}), 80-100 \%$ (10-12 min), hold at $100 \%$ (12-14 min), $100 \%$ to 0 (14$24 \mathrm{~min}$ ). The UV detector was set to $450 \mathrm{~nm}$ for both lutein and zeaxanthin.

\section{Centrifugal partition chromatography}

Purification of lutein and zeaxanthin was carried out in a preparative centrifugal partition chromatography column (Model SPOT SCPC-250, ARMEN Instruments, SaintAvé, France). The two-phase solvent system consisted of

Table 1 Test to determine suitable solvent for lutein and zeaxanthin extraction and purification

\begin{tabular}{lclllcc}
\hline Solvent & $\begin{array}{l}\text { Wt. of kemin } \\
\text { sample }(\mathbf{m g})\end{array}$ & $\begin{array}{l}\text { Vol. of solvent } \\
\text { (L) }\end{array}$ & $\begin{array}{l}\text { Concentration lutein } \\
\text { (mg/L) }\end{array}$ & $\begin{array}{l}\text { Concentration } \\
\text { zeaxanthin }(\mathbf{m g} / \mathbf{L})\end{array}$ & $\begin{array}{l}\text { Yield lutein (\%) } \\
\begin{array}{l}\text { Yield } \\
\text { zeaxanthin } \\
(\%)\end{array}\end{array}$ \\
\hline Ethanol & 10.1 & 0.02 & 77.03 & 4.34 & 15.25 & 0.86 \\
Ethyl acetate & 9.8 & 0.02 & 71.76 & 4.16 & 14.64 & 0.85 \\
Methanol & 10 & 0.02 & 50.34 & 2.81 & 8.07 & 0.56 \\
Acetonitrile & 9.8 & 0.02 & 43.2 & 2.38 & 7.93 & 0.49 \\
Water & 9.8 & 0.02 & 38.88 & 2.19 & 0.45 \\
\hline
\end{tabular}

Lutein and zeaxanthin were most soluble in ethanol 
$n$-heptane:ethanol:water $(5: 3: 1, v / v / v)$. The column was operated in ascending mode at 1800 RPM. The filtered sample mixture solution $(10 \mathrm{~mL})$ was injected after the system has been equilibrated. The mobile phase flow rate was set to $3.5 \mathrm{~mL} / \mathrm{min}$ flow rate for $120 \mathrm{~min}$. The effluent from the outlet of the CPC column was continuously detected by UV (Visacon's VUV-24) at $450 \mathrm{~nm}$ and collected in glass culture tubes with a fraction collector (Foxy R1, Teledyne Isco) set to collect one tube per minute.

\section{Results and discussion}

\section{Extraction and quantification}

\section{Extraction conditions}

A Soxhlet extraction experiment was devised to determine the most suitable conditions to recover lutein and zeaxanthin from DDGS. Samples of extract solution were removed from the round-bottom flask in $2 \mathrm{~mL}$ aliquots at various times depending on the experiment. Initial study focused on the particle size for optimal lutein and zeaxanthin recovery; samples were taken every $2 \mathrm{~h}$ for up to $12 \mathrm{~h}$. Samples were dried and analyzed for lutein and zeaxanthin content on HPLC. The results of the initial particle size study (Fig. 1) indicate that of the sizes tested, a 60-mesh particle size allows for the most suitable recovery in terms of mass of lutein and zeaxanthin to be extracted from the DDGS. A subsequent study to determine favorable extraction time used the 60-mesh ground DDGS. As the objective was to determine the quantity of lutein and zeaxanthin in DDGS, solvent loss during sampling had to be considered. The extraction was performed over the course of $12 \mathrm{~h}$ and the ethanol extraction solvent was replaced every $4 \mathrm{~h}$ with fresh ethanol. Table 2 shows that most all of the extraction, $100 \%$ of lutein and $96.41 \%$ of zeaxanthin, occurs during the first $4 \mathrm{~h}$. The initial extraction experiments determined that a small particle size and short extraction time was most suitable for lutein and zeaxanthin recovery.

\section{Quantification of lutein and zeaxanthin in DDGS}

Analysis of the Soxhlet extracts allowed for initial quantification lutein and zeaxanthin present in DDGS oleoresin. It was determined that, at the most favorable Soxhlet extraction conditions, the DDGS oleoresin contained $0.0429 \pm 0.0121 \mathrm{mg}$ lutein/g dry DDGS and $0.0176 \pm 0.0041 \mathrm{mg}$ zeaxanthin/g dry DDGS.
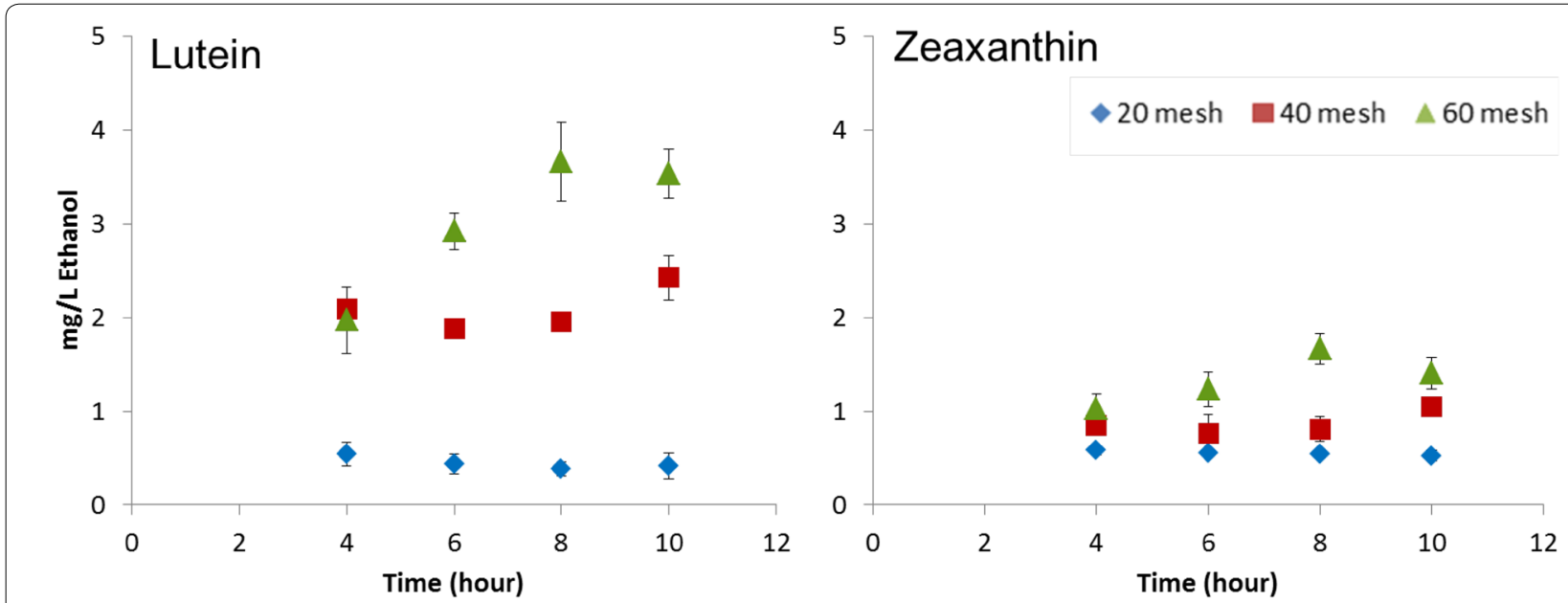

Fig. 1 Soxhlet extraction of DDGS with particle size ranging from 20 to 60 mesh. Both lutein and zeaxanthin were optimally extracted at the smallest particle size. Therefore, 60 mesh was chosen for subsequent experiments

Table 2 The measured concentration of lutein and zeaxanthin in both DDGS and oleoresin

\begin{tabular}{|c|c|c|c|c|c|c|c|}
\hline \multirow[t]{2}{*}{ Time (h) } & \multirow[t]{2}{*}{ Oleoresin (g) } & \multicolumn{2}{|c|}{$\mu \mathrm{g} / \mathrm{g}$ wet DDGS } & \multicolumn{2}{|c|}{$\mu \mathrm{g} / \mathrm{g}$ oleoresin } & \multicolumn{2}{|c|}{$\%$ extracted } \\
\hline & & Lutein & Zeaxanthin & Lutein & Zeaxanthin & Lutein & Zeaxanthin \\
\hline 4 & 1.96 & 15.145 & 11.793 & 61.945 & 48.218 & 100.00 & 96.410 \\
\hline 8 & 0.8 & None & 0.439 & None & 0.005 & None & 3.590 \\
\hline 12 & 0.2 & None & None & None & None & None & None \\
\hline
\end{tabular}

The crude extraction solution was replaced with fresh ethanol every $4 \mathrm{~h}$. The result indicates that four hours is a sufficient time-frame to recover lutein and zeaxanthin from DDGS 
When comparing to the current source of lutein and zeaxanthin, Tagetes erecta petals, the values determined from Soxhlet extraction were an order of magnitude lower. The concentration of lutein in of marigold petal oleoresin varies from 5 to $50 \%$ (Hadden et al. 1999) but also differs among its subspecies (Lin et al. 2015). Lutein or lutein ester in marigold yellow flower is $21.22 \pm 0.54 \mathrm{mg} /$ dry mass (Bhattacharyya et al. 2010). However, the quantity found in commercial marigold flower is much lower, $1.75 \pm 0.06 \mathrm{mg} / \mathrm{g}$ dry mass (Sivel et al. 2014). Reports have indicated that microalgae may also serve as a potential source for lutein; microalgae contains anywhere from 4 to $6 \mathrm{mg}$ (Blanco et al. 2007), $10.4 \mathrm{mg}$ (Cerón et al. 2008), or 1.75-1.95 mg (Wei et al. 2008) of lutein per gram of dry matter. In species of maize, the content also has been reported to range from $0.87 \mu \mathrm{g}$ of lutein and $6.43 \mu \mathrm{g}$ of zeaxanthin per gram dry mass of maize (Panfili et al. 2004), to $6.44 \mu \mathrm{g}$ lutein and $4.42 \mu \mathrm{g}$ zeaxanthin per gram dry mass of maize (Kean et al. 2011). While the quantity of lutein and zeaxanthin

Table 3 Comparison of lutein (L) and zeaxanthin (Z) in marigold, corn, and DDGS

\begin{tabular}{lll}
\hline Source & Content $\mathbf{( m g / g}$ dry mass) & References \\
\hline Marigold flower & $152.23 \pm 0.45(\mathrm{~L})$ & Bhattacharyya et al. (2010) \\
& $1.75 \pm 0.06(\mathrm{~L})$ & Sivel et al. (2014) \\
Corn/maize & $0.87 \times 10^{-3}(\mathrm{~L}), 6.43 \times 10^{-3}$ & Panfili et al. (2004) \\
& $(\mathrm{Z})$ & \\
& $6.44 \times 10^{-3}(\mathrm{~L}), 4.42 \times 10^{-3}$ & Kean et al. (2011) \\
& $(\mathrm{Z})$ & \\
DDGS & $42.9 \times 10^{-3}(\mathrm{~L}), 17.6 \times 10^{-3}$ & (Current work) \\
& $(\mathrm{Z})$ &
\end{tabular}

It is evident that the processing required to produce DDGS concentrates the lutein and zeaxanthin content is inherently lower in maize than in the marigold flower or even microalgae, the concentrated oleoresin from DDGS may justify the conversion of a portion of this marginally valuable resource into a high-value by-product. The major benefit to recovery of lutein and zeaxanthin from DDGS is that no additional harvesting is required as DDGS is already presently used in an industrial process. A portion DDGS could be funneled to a lutein and zeaxanthin extraction step and would require minimal processing steps required for recovery. Table 3 summarizes lutein and zeaxanthin content in marigold and maize and is included as a comparison for the presence of these compounds in DDGS. The concentration of lutein and zeaxanthin in the DDGS is three to five times greater than in corn indicating that the processing required to produce DDGS acts to concentrate the lutein and zeaxanthin.

\section{Compositional analysis}

A compositional analysis was performed to determine how the extraction process may affect the quality of the DDGS. A summary of the average composition (dry basis) of DDGS pre- and post extraction is shown in Table 4. A pooled $t$ test was performed using JMP 13 (SAS Institute, Cary, NC) to compare variation within each component of pre- and post- extraction samples and to substantiate the effect of extraction on feed quality. For the pre-extraction DDGS, the acid detergent fiber (ADF), which refers to the cell wall portions of the forage that are mainly made up of cellulose (10.6\%) and lignin (4.3\%) accounts for $16.1 \%$ of the dry mass. The neutral detergent fiber (NDF), which is the total cell wall, comprised the ADF fraction plus hemicellulose (19.1\%) accounts for $37.3 \%$ of the total mass. The remaining dry matter

Table 4 Results of compositional analysis of DDGS pre- and post-ethanol extraction

\begin{tabular}{lccc}
\hline & Pre-extraction DDGS & Post-extraction DDGS & Prob $>|\boldsymbol{t}|$ \\
\hline Moisture & 9.86 & $5.27 \pm 0.29$ & $94.73 \pm 0.29$ \\
Dry matter & 90.11 & & $0.29 \pm 0.27$ \\
Crude fat & Dry basis & 0.39 & 0.0083 \\
Ash & 10.39 & $5.02 \pm 0.10$ & 0.0002 \\
Lignin & 3.64 & $3.37 \pm 0.09$ & 0.0095 \\
Neutral detergent fiber (NDF) & 4.3 & $45.87 \pm 0.81$ & 0.0198 \\
Cellulose & 37.3 & $14.63 \pm 0.69$ & 0.02 \\
Hemicellulose & 10.6 & $19.63 \pm 8.93$ & 0.0545 \\
Acid detergent fiber (ADF) & 19.1 & $18.83 \pm 0.66$ & 0.09702 \\
Total starch & 16.1 & $4.01 \pm 0.10$ & 0.0995 \\
Crude fiber & 3.88 & $16.43 \pm 5.78$ & 0.4392 \\
\hline
\end{tabular}

Prob $>|t|$ indicates if there is a significant difference in samples pre- and post-extraction. If Prob $>|t|$ is greater than 0.05 , than there is no significant difference and the process does not impact these particular variables 
was starch (3.88\%), crude fat (10.39\%), and ash (3.64\%). The post-extraction sample results are also shown in Table 4. The values for the pooled $t$ test are reported in Table 4. If Prob $>|t|$ is greater than 0.05 than there is no significant difference in pre- and post-extraction results. Overall, the hemicellulose, ADF, total starch, and crude fiber are not significantly impacted by the extraction process. As expected, crude fat is significantly extracted by the ethanol as evidenced by the oleoresin that is visible post-extraction. The compositional analysis indicates that extraction process does not negatively impact the digestibility of the DDGS with regards to ADF. Digestibility is often reported in terms of ADF as there is an inverse relationship in ADF content-as ADF increases, digestibility decreases-our process indicates no significant change in ADF (Kim et al. 2008).

\section{CPC purification}

\section{Solvent system selection}

The second objective of this study was to use CPC to purify the lutein and zeaxanthin from the other compounds extracted during Soxhlet. It was not necessary to purify lutein and zeaxanthin, individually since they are often administered together (Mares-Perlman et al. 2002), but it is compelling to provide a clean source of lutein and zeaxanthin after a single purification step. CPC is a useful technique for natural products purification (Marston and Hostettmann 2006; Friesen and Pauli 2008). Solvent system selection is crucial for a quality CPC purification. Previous studies using a countercurrent chromatographic technique were the baseline for selecting a suitable solvent system. Table 5 summarizes solvent systems used in previous studies to purify lutein and zeaxanthin recovered from various plant sources. To identify the 'best solvent' and measure the partition coefficient, $K_{D}$, of selected solvent system, five solvents (heptane, water, acetonitrile, ethanol, ethyl acetate, and methanol) commonly used in making solvent system for separating polar
Table 6 Partition coefficients and separation factors of lutein and zeaxanthin from variation on a solvent system of $\boldsymbol{n}$-heptane/ethanol/water

\begin{tabular}{lllll}
\hline $\begin{array}{l}n \text {-heptane/ } \\
\text { ethanol/water } \\
\text { ratio (v/v) }\end{array}$ & $\begin{array}{l}\text { Partition } \\
\text { coefficient, } \boldsymbol{K}_{\boldsymbol{D}}\end{array}$ & $\begin{array}{l}\text { Separation } \\
\text { factor, } \boldsymbol{\alpha}\end{array}$ & Settling time (s) \\
\cline { 2 - 4 } & Lutein & Zeaxanthin & & \\
\hline $6: 5: 1.3$ & 1.527 & 1.658 & 1.086 & 6 \\
$5: 3: 1$ & 0.891 & 1.016 & 1.140 & 5 \\
$4: 3: 1$ & 0.988 & 1.150 & 1.164 & $5-7$ \\
$4: 3: 2$ & 0.151 & 0.167 & 1.111 & $5-7$ \\
$6: 5: 1.2$ & 0.606 & 0.522 & 1.162 & $\sim 10$ \\
$6: 5: 1.5$ & 0.357 & 0.374 & 1.049 & 6 \\
$6: 4.5: 1.5$ & 0.268 & 0.277 & 1.034 & $7-8$ \\
\hline
\end{tabular}

compounds were tested through shake-flask experiment using the Kemin carotenoid sample. $K_{D}$ is the concentration of the solute in the upper phase divided by the concentration of the solute in the lower phase. Lutein and zeaxanthin are both soluble in ethanol followed by ethyl acetate as shown in Table 1. Solvent systems consisting of $n$-heptane, ethanol, ethyl acetate, and water at various volumetric ratios were used to calculate $K_{D}$ to determine which would be most suitable for CPC fractionation. For an acceptable solvent system, three criteria are considered: (1) $K_{D}$ should fall in the range should be between 0.4 and 2.5 (Friesen and Pauli 2005), (2) separation factor, a, should be greater than 1.5 (Marston and Hostettmann 2006), and (3) the settling time should be less than $30 \mathrm{~s}$ (Marston and Hostettmann 2006). The separation factor, $\alpha$, is equal to $K_{D, i} / K_{D, j}$ when $K_{D, j}>K_{D, i}$, where $K_{D, i}$ is the partition coefficient for component $i$ and $K_{D, j}$ is the partition coefficient for component $j$ (Engelberth et al. 2010). The settling time is the time required for two phases to appear after gentle agitation (Ito 2005). The Kemin sample was tested in seven $n$-heptane/ethanol/water solvent systems of varying volumetric ratios. Table 6 displays the results of the Kemin test; note that all results satisfy the

Table 5 Published solvent systems used for lutein and zeaxanthin purifications

\begin{tabular}{|c|c|c|c|}
\hline Source & Extract compounds & Solvent system (volumetric ratio) & $K_{D}$ \\
\hline Spinach (Aman et al. 2005) & Lutein, zeaxanthin & n-hexane/ethanol/water (6:5:1.3) & $\begin{array}{l}0.77(\mathrm{~L}) \\
0.60(\mathrm{Z})\end{array}$ \\
\hline Sweet corn (Aman et al. 2005) & Lutein, zeaxanthin & n-hexane/ethanol/water (6:5:1.3) & $\begin{array}{l}0.77(\mathrm{~L}) \\
0.60(\mathrm{Z})\end{array}$ \\
\hline Dietary supplement (Aman et al. 2005) & Lutein, zeaxanthin & n-hexane/ethanol/water (6:5:1.3) & $\begin{array}{l}0.77(\mathrm{~L}) \\
0.60(\mathrm{Z})\end{array}$ \\
\hline Marigold flower (Wei et al. 2003) & Lutein & n-heptane/chloroform/acetonitrile (10:3:7) & $0.611(\mathrm{~L})$ \\
\hline Microalgae (Li et al. 2001) & Lutein & n-hexane/ethanol/water (4:3:1) & $0.538(\mathrm{~L})$ \\
\hline Microalgae (Chen et al. 2005) & Zeaxanthin & n-hexane/ethyl acetate/ethanol/water (8:2:7:3) & $1.384(Z)$ \\
\hline
\end{tabular}

Knowledge of previously used solvent systems aid in selection of a suitable solvent system 
partition coefficient criteria. The 5:3:1 ( $n$-heptane/etha$\mathrm{nol} /$ water) was chosen to for CPC purification as it had a short settling time, a high separation factor, and had a greater polarity range.

\section{CPC fractionation development}

Trial CPC fractionation and method development was conducted using the Kemin carotenoid sample with the $n$-heptane/ethanol/water $(5: 3: 1, v / v / v)$ solvent system. For CPC fractionation, $1 \mathrm{~g}$ of Kemin carotenoid sample was dissolved into $8 \mathrm{~mL}$ of the $n$-heptane/ethanol/water $(5: 3: 1, v / v / v)(4 \mathrm{~mL}$ of upper phase and $4 \mathrm{~mL}$ of lower phase). The sample was then filtered using a $0.2 \mu \mathrm{m}$ Pall Nylon Acrodisc filter to remove any undissolved solids. As stated in the materials section, the sample from Kemin contained a variety of compounds and it was only disclosed that the sample was concentrated with lutein and zeaxanthin. The rotational speed and solvent flow rate were adjusted to $1800 \mathrm{RPM}$ and $3.5 \mathrm{~mL} / \mathrm{min}$, respectively.

Fractionation of the oleoresin on CPC used methods developed for the Kemin sample. DDGS oleoresin (3.67 g) was dissolved in $10 \mathrm{~mL}$ of $\mathrm{CPC}$ solvent as before and then injected into CPC at the start of the method. The eluent was collected via a fraction collector at one tube per minute. Each fraction was then dried down, reconstituted in HPLC mobile phase, and analyzed for lutein and zeaxanthin content by HPLC. The trend of the resulting lutein and zeaxanthin content at each time point is shown in Fig. 2. Lutein and zeaxanthin elute in a bell shape with offset peak maxima. Peak overlap is noticeable, but there is $\sim 5$ min window where lutein elutes with negligible zeaxanthin in the fraction. The close elution time is to be expected since the separation factor in the CPC solvent system is close to one. The elution profile in Fig. 2 indicates that the highest quantity of lutein and zeaxanthin collected in the fraction was achieved at $94 \mathrm{~min}$ $(0.0067 \mathrm{mg})$ and $103 \mathrm{~min}(0.0029 \mathrm{mg})$, respectively. The total recovery of lutein and zeaxanthin from the DDGS oleoresin by CPC was 0.141 and $0.065 \mathrm{mg}$, respectively.

As stated, CPC purification was not intended to purify lutein and zeaxanthin from one another, but rather from the other extractives. Figure 3 displays a set of chromatograms: crude extract and peak maxima of the lutein and zeaxanthin fractions. The crude extract (Fig. 3a) shows a variety of peaks along with the desired compounds. A probable identity of one of the first initial peaks is that of an epoxide (Khachik et al. 1992); note that the epoxide and

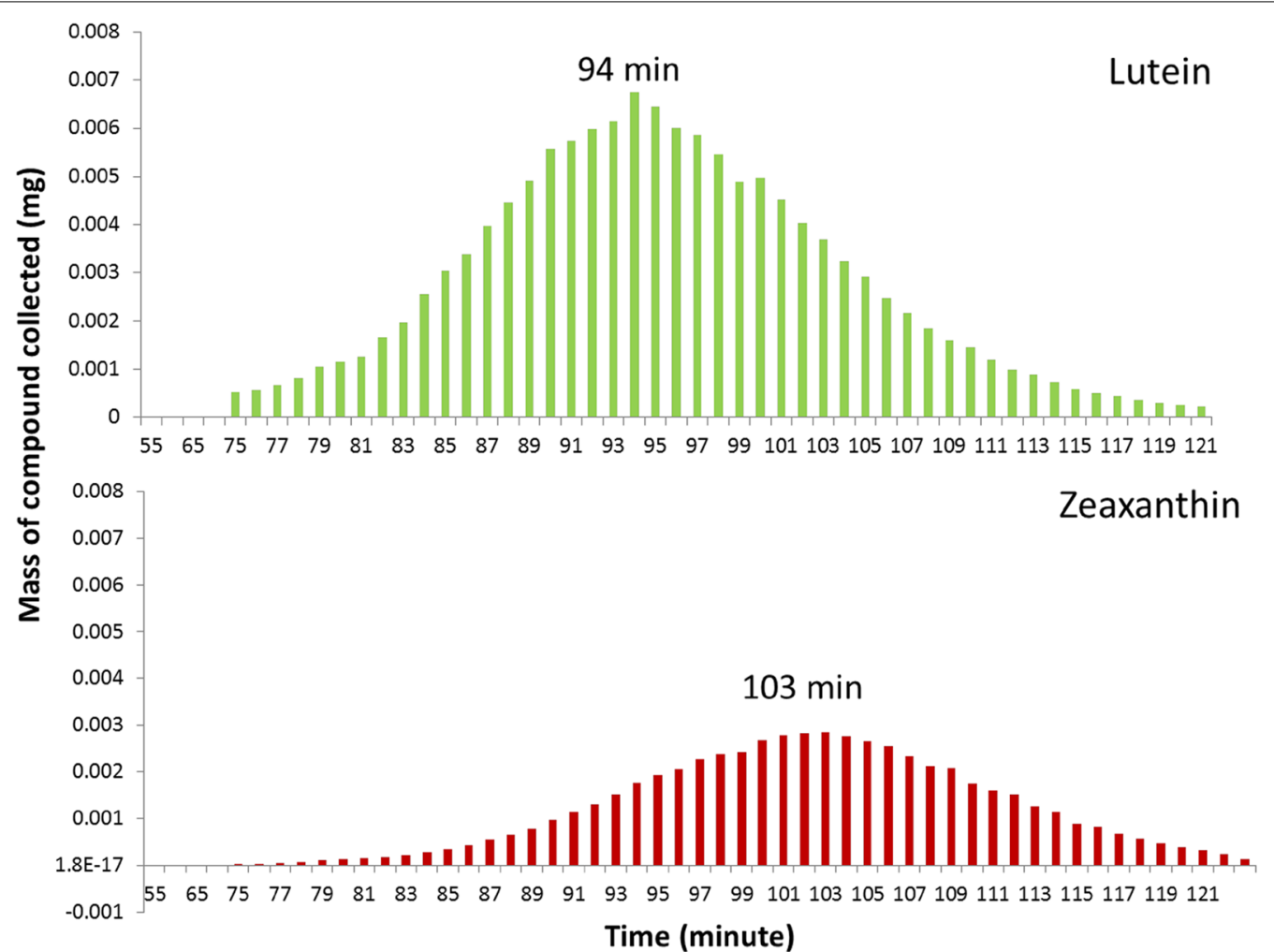

Fig. 2 Elution profile of lutein and zeaxanthin fractions from CPC purification. A fraction was collected each minute and analyzed via HPLC. The highest quantity of lutein and zeaxanthin collected in the fraction was achieved at $94 \mathrm{~min}(0.0067 \mathrm{mg})$ and $103 \mathrm{~min}(0.0029 \mathrm{mg})$, respectively 

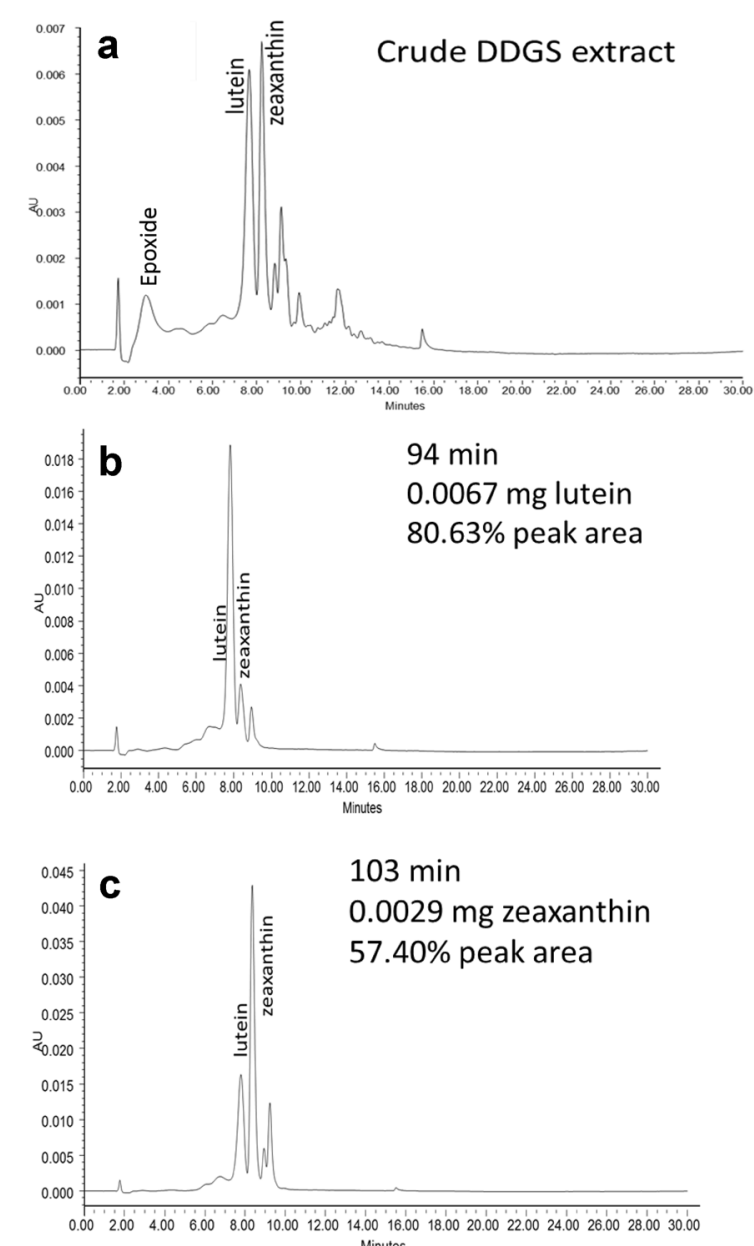

Minutes

Fig. 3 HPLC analyses of the lutein and zeaxanthin peak from CPC trace: a displays the crude DDGS sample extract from Soxhlet extraction, in which the area \% of lutein peak is $28.11 \%$ and zeaxanthin's is $20.42 \%$, $\mathbf{b}$ is minute 94 with $L$ at $80.63 \%$ purity and $Z$ at $10.91 \%$, and $\mathbf{c}$ is minute 103 where Zeaxanthin had its maximum elution with peak area $\%$ at 57.40 and $19.19 \%$ for lutein

many of the other unidentified compounds are no longer observable in the other $\mathrm{CPC}$ fractions (Fig. 3b, c). The formation of intracellular epoxides can be toxic to a cells functionality (Ehrenberg and Hussain 1981) and should be avoided in a lutein and zeaxanthin dietary supplement. CPC fractionation can provide the necessary single-step purification to remove lutein and zeaxanthin from the other compounds extracted during the Soxhlet process. A CPC separation can yield fractions free of undesired compounds.

\section{Conclusions}

This present study quantified the bulk of lutein and zeaxanthin remaining in DDGS through Soxhlet extraction at what was determined the most favorable conditions. There remains $36.09 \pm 16.87 \mu \mathrm{g}$ of lutein and $15.48 \pm 6.13 \mu \mathrm{g}$ of zeaxanthin per gram of DDGS. This is a demonstrated three to fivefold increase in concentration as compared to corn itself. Compositional analysis of the DDGS indicates that digestibility, with regard to acid detergent fiber, will not be impacted by the additional processing step. Furthermore, CPC was shown to be a suitable technique to isolate the lutein and zeaxanthin from the remaining extractives with purities at 80.64 and $57.40 \%$, respectively. Further study into solvent system selection and CPC mode operation are required if it were desired to create pure lutein and pure zeaxanthin fractions. As it stands, isolation of these two compounds from one another is not necessary for the dietary supplement market as these lutein and zeaxanthin are present together both in nature and in the human body. Recovery of lutein and zeaxanthin from DDGS would enable a new market stream within the dry-grind process and could be done in a way that does not diminish or downgrade the quality of the DDGS.

\section{Abbreviations}

ADF: acid detergent fiber; CPC: centrifugal partition chromatography; DDGS: distillers dried grain with solubles; HPLC: high-performance liquid chromatography; NDF: neutral detergent fiber; $K_{D}$ : partition coefficient; $a$ : separation factor.

\section{Authors' contributions}

$J L$ and ASE conceived and designed the experiments. JL performed the experiments. JL and ASE wrote the paper. Both authors read and approved the final manuscript.

\section{Author details}

${ }^{1}$ Laboratory of Renewable Resources Engineering, Department of Agricultural and Biological Engineering, Purdue University, Potter Engineering Building, Room 216, 500 Central Drive, West Lafayette, IN 47907, USA. ${ }^{2}$ Environmental and Ecological Engineering, Purdue University, Room 364, Potter Engineering Building, 500 Central Drive, West Lafayette, IN 47907, USA.

\section{Acknowledgements}

The authors would like to thank Drs. Nathan Mosier and Mario Feruzzi for guidance on this project, as well as Darwin Ortiz for his advice on experimental setup and instrument use.

\section{Competing interests}

The authors declare that they have no competing interests.

\section{Availability of data and materials}

The datasets supporting the conclusions of this article are included within the article.

\section{Consent for Publication}

Not applicable.

Ethics approval and consent to participate Not applicable.

Funding

Funding for this research was awarded by the Indiana Corn Marketing Council (ICMC). 


\section{Publisher's Note}

Springer Nature remains neutral with regard to jurisdictional claims in published maps and institutional affiliations.

Received: 17 April 2018 Accepted: 4 July 2018

Published online: 14 July 2018

\section{References}

Aman R, Carle R, Conrad J, Beifuss U, Schieber A (2005) Isolation of carotenoids from plant materials and dietary supplements by high-speed countercurrent chromatography. J Chromatogr A 1074:99-105. https://doi. org/10.1016/j.chroma.2005.03.055

BCC Research (2011) The global market for carotenoids. BCC Research, Wellesley

Belyea RL, Rausch KD, Tumbleson ME (2004) Composition of corn and distillers dried grains with solubles from dry grind ethanol processing. Bioresour Technol 94:293-298. https://doi.org/10.1016/j.biortech.2004.01.001

Bhattacharyya S, Datta S, Mallick B, Dhar P, Ghosh S (2010) lutein content and in vitro antioxidant activity of different cultivars of indian marigold flower (Tagetes patula L.) extracts. J Agric Food Chem 58:8259-8264. https://doi. org/10.1021/jf101262e

Blanco AM, Moreno J, Del Campo JA, Rivas J, Guerrero MG (2007) Outdoor cultivation of lutein-rich cells of Muriellopsis sp. in open ponds. Appl Microbiol Biotechnol 73:1259-1266. https://doi.org/10.1007/s0025 3-006-0598-9

Bone RA, Landrum JT, Tarsis SL, LandBone RA, Landrum JT, Tarsis SL (1985) Preliminary identification of the human macular pigment. Vision Research 25(11):1531-1535. https://doi.org/10.1016/0042-6989(85)90123-3

Bregendahl K (2008) Use of distillers co-products in diets fed to poultry. In: Babcock B, Hayes D, Lawrence J (eds) Using distillers grains in the U.S. and international livestock and poultry industries. CARD Books, Ames, pp 99-133

Cerón MC, Campos I, Sánchez JF, Acién FG, Molina E, Fernández-Sevilla JM (2008) Recovery of lutein from microalgae biomass: development of a process for Scenedesmus almeriensis biomass. J Agric Food Chem 56:11761-11766. https://doi.org/10.1021/jf8025875

Chauveau-Duriot B, Doreau M, Nozière P, Graulet B (2010) Simultaneous quantification of carotenoids, retinol, and tocopherols in forages, bovine plasma, and milk: validation of a novel UPLC method. Anal Bioanal Chem 397:777-790. https://doi.org/10.1007/s00216-010-3594-y

Chen F, Li H-B, Wong RN-S, Ji B, Jiang Y (2005) Isolation and purification of the bioactive carotenoid zeaxanthin from the microalga Microcystis aeruginosa by high-speed counter-current chromatography. J Chromatogr A 1064:183-186. https://doi.org/10.1016/j.chroma.2004.12.065

Delgado-Vargas F, Paredes-López O (1996) Correlation of HPLC and AOAC methods to assess the all-trans-lutein content in marigold flowers. J Sci Food Agric 72:283-290. https://doi.org/10.1002/ (sici)1097-0010(19961 1)72:3<283::aid-jsfa652>3.0.co;2-v

Delgado-Vargas F, Paredes-López O (2002) Natural colorants for food and nutraceutical uses. CRC Press, Hoboken

Ehrenberg L, Hussain S (1981) Genetic toxicity of some important epoxides. Mutat Res Genet Toxicol 86:1-113. https://doi.org/10.1016/01651110(81)90034-8

Engelberth AS, Clausen EC, Carrier DJ (2010) Comparing extraction methods to recover ginseng saponins from American ginseng (Panax quinquefolium), followed by purification using fast centrifugal partition chromatography with HPLC verification. Sep Purif Technol 72:1-6. https://doi. org/10.1016/j.seppur.2009.12.002

Fernández-Sevilla JM, Acién Fernández FG, Molina Grima E (2010) Biotechnological production of lutein and its applications. Appl Microbiol Biotechnol 86:27-40. https://doi.org/10.1007/s00253-009-2420-y

Friesen JB, Pauli GF (2005) G.U.E.S.S. - a generally useful estimate of solvent systems for CCC. J Liq Chromatogr Relat Technol 28:2777-2806. https:// doi.org/10.1080/10826070500225234

Friesen JB, Pauli GF (2008) Performance characteristics of countercurrent separation in analysis of natural products of agricultural significance. J Agric Food Chem 56:19-28. https://doi.org/10.1021/jf072415a
Fullmer LA, Shao A (2001) The role of lutein in eye health and nutrition. Cereal Foods World 46(9):408-413

Hadden W, Watkins RH, Levy L, Regalado E, Rivadeneira DM, van Breemen R, Schwartz SJ (1999) Carotenoid composition of marigold (Tagetes erecta) flower extract used as nutritional supplement. J Agric Food Chem 47:4189-4194

Ito Y (2005) Golden rules and pitfalls in selecting optimum conditions for highspeed counter-current chromatography. J Chromatogr A 1065:145-168. https://doi.org/10.1016/j.chroma.2004.12.044

John JH, Yudkin S, Neil P, Ziebland LS, Roe HAW, Neil HAW (2002) Effects of fruit and vegetable consumption on plasma antioxidant concentrations and blood pressure: a randomised controlled trial. Lancet 359:1969-1974. https://doi.org/10.1016/S0140-6736(02)98858-6

Johnson E, Neuringer M, Russell RM, Schalch W, Snodderly DM (2005) Nutritional manipulation of primate retinas, III: effects of lutein or zeaxanthin supplementation on adipose tissue and retina of xanthophyll-free monkeys. Invest Ophthalmol Vis Sci 46:692-702. https://doi.org/10.1167/ iovs.02-1192

Kean EG, Bordenave N, Ejeta G, Hamaker BR, Ferruzzi MG (2011) Carotenoid bioaccessibility from whole grain and decorticated yellow endosperm sorghum porridge. J Cereal Sci 54:450-459. https://doi.org/10.1016/j. jcs.2011.08.010

Khachik F (2001) Process for extraction and purification of lutein, zeaxanthin and rare carotenoids from marigold flowers and plants. US 6,262,284 B1 17 July 2001

Khachik F, Goli MB, Beecher GR, Holden J, Lusby WR, Tenorio MD, Barrera MR (1992) Effect of food preparation on qualitative and quantitative distribution of major carotenoid constituents of tomatoes and several green vegetables. J Agric Food Chem 40:390-398. https://doi.org/10.1021/jf000 $15 \mathrm{a} 006$

Kim Y, Mosier NS, Hendrickson R, Ezeji T, Blaschek H, Dien B, Cotta M, Dale B, Ladisch MR (2008) Composition of corn dry-grind ethanol by-products: DDGS, wet cake, and thin stillage. Bioresour Technol 99:5165-5176. https ://doi.org/10.1016/j.biortech.2007.09.028

Koushan K, Rusovici R, Li W, Ferguson LR, Chalam KV (2013) The role of lutein in eye-related disease. Nutrients 5:1823-1839. https://doi.org/10.3390/ nu5051823

Kurilich AC, Juvik JA (1999) Quantification of carotenoid and tocopherol antioxidants in Zea mays. J Agric Food Chem 47(5):1948-1955. https:// doi.org/10.1021/jf981029d

Li HB, Chen F, Zhang TY, Yang FQ, Xu GQ (2001) Preparative isolation and purification of lutein from the microalga Chlorella vulgaris by high-speed counter-current chromatography. J Chromatogr A 905:151-155. https:// doi.org/10.1016/S0021-9673(00)00987-0

Li S, Tayie FAK, Young MF, Rocheford T, White WS (2007) Retention of provitamin A carotenoids in high beta-carotene maize (Zea mays) during traditional African household processing. J Agric Food Chem 55:10744-10750. https://doi.org/10.1021/jf071815v

Lin JH, Lee DJ, Chang JS (2015) Lutein production from biomass: marigold flowers versus microalgae. Bioresour Technol 184:421-428. https://doi. org/10.1016/j.biortech.2014.09.099

Malinow MR, Feeney-Burns L, Peterson LH, Klein ML, Neuringer M (1980) Diet-related macular anomalies in monkeys. Investig Ophthalmol Vis Sci 19:857-863

Mares-Perlman JA, Millen AE, Ficek TL, Hankinson SE (2002) The body of evidence to support a protective role for lutein and zeaxanthin in delaying chronic disease. Overview. J Nutr 132:518S-524S

Marston A, Hostettmann K (2006) Developments in the application of countercurrent chromatography to plant analysis. J Chromatogr A 1112:181-194. https://doi.org/10.1016/j.chroma.2005.10.018

Mozaffarieh M, Sacu S, Wedrich A (2003) The role of the carotenoids, lutein and zeaxanthin, in protecting against age-related macular degeneration: a review based on controversial evidence. Nutr J 2:20. https://doi. org/10.1186/1475-2891-2-20

Panfili G, Fratianni A, Irano M (2004) Improved normal-phase high-performance liquid chromatography procedure for the determination of carotenoids in cereals. J Agric Food Chem 52:6373-6377. https://doi. org/10.1021/jf0402025

Piccaglia R, Marotti M, Grandi S (1998) Lutein and lutein ester content in different types of Tagetes patula and T. erecta. Ind Crops Prod 8:45-51. https:// doi.org/10.1016/S0926-6690(97)10005-X 
Sivel M, Kracmar S, Fisera M, Klejdus B, Kuban V (2014) Lutein content in marigold flower (Tagetes erecta L.) concentrates used for production of food supplements. Czech J Food Sci 32:521-525

Sluiter A, Ruiz R, Scarlata C, Sluiter J, Templeton D (2008) Determination of extractives in biomass. Laboratory analytical procedure (LAP). Technical report: NREL/TP-510-42619

Sommerburg O, Keunen JE, Bird AC, van Kuijk FJ (1998) Fruits and vegetables that are sources for lutein and zeaxanthin: the macular pigment in human eyes. Br J Ophthalmol 82:907-910

Sun H, Lee EJ, Samaraweera H, Persia M, Ahn DU (2013) Effects of increasing concentrations of corn distillers dried grains with solubles on chemical composition and nutrient content of egg. Poult Sci 92:233-242. https:// doi.org/10.3382/ps.2012-02346
Wei Y, Zhang T, Xu G, Ito Y (2003) Application of CCC for the separation of lutein from a crude extract of marigold flower petals. J Liq Chromatogr Relat Technol 26:1659-1669. https://doi.org/10.1081/JLC-120021274

Wei D, Chen F, Chen G, Zhang X, Liu L, Zhang H (2008) Enhanced production of lutein in heterotrophic Chlorella protothecoides by oxidative stress. Sci China C Life Sci 51:1088-1093. https://doi.org/10.1007/s1142 7-008-0145-2

\section{Submit your manuscript to a SpringerOpen ${ }^{\circ}$ journal and benefit from:}

- Convenient online submission

- Rigorous peer review

- Open access: articles freely available online

- High visibility within the field

- Retaining the copyright to your article

Submit your next manuscript at $\boldsymbol{\nabla}$ springeropen.com 